\title{
EFFECT OF PRIMARY STENTING OF CORONARY ARTERIES ON CLINICAL COURSE AND REMODELING OF THE LEFT VENTRICLE IN PATIENTS WITH ACUTE ST SEGMENT ELEVATION MYOCARDIAL INFARCTION (RESULTS AFTER 12 MONTHS)
}

DOI: 10.36740/WLek202001112

\author{
Yurii P. Melen ${ }^{2}$, Vasyl A. Skybchik', Maryana Y. Fedechko' ${ }^{1}$, Lesya M. Kopchak ${ }^{1}$ \\ 'LVIV NATIONAL MEDICAL UNIVERSITY NAMED AFTER DANYLO HALYTSKY, LVIV, UKRAINA \\ 2KNP «CLINICAL HOSPITAL OF AMBULANCE LVIV», LVIV, UKRAINA
}

\begin{abstract}
The aim: To determine the predictive effect of primary stenting of coronary artery on the clinical course and features of left ventricular remodeling in patients with acute myocardial infarction (MI) with ST segment elevation and LV diastolic dysfunction (DD) in the remote period (12 months).

Materials and methods: The study included 80 patients with STEMI who undergo primary PCI (group 1) and 20 patients with STEMI who did not undergo myocardial revascularization (group 2). In both groups, the levels of NT-proBNP were determined, echocardiography, bicycle ergometry; quality of life was determined according to SAQ questionnaire scales; marked cardiovascular complications. Patients were re-examined after 12 months.

Results: The average level of NT-proBNP for 5 days and 12 months of patients in group 1 significantly decreased $-434.6 \pm 36.3$ and $122.8 \pm 4.13 \mathrm{~g} / \mathrm{ml}(\mathrm{p}<0.001)$, indicating a less pronounced late remodeling of $L \mathrm{~V}$ in patients undergoing revascularization with STEMI. Diastolic function was evaluated by $E / A$ and DT. After 12 months, the 1 st group was markedly lower than E/A and DT compared to the $2 \mathrm{nd}-0.76 \pm 0.03$ and $198 \pm 4.7 \mathrm{~m} / \mathrm{s}$ and $1.49 \pm 0.01$ and $135,3 \pm 2.91 \mathrm{~m} / \mathrm{s}$, respectively ( $<<0.05)$, which characterizes a decrease in the parameters of the DD by the type of the relaxation processes of the left ventriculi. Patients in Group 1, according to SAQ scales, had better quality of life and higher exercise tolerance at I-II level than patients without revascularization.

Conclusions: In patients with STEMI, after a primary stenting of coronary artery, a significantly lower NT-proBNP level and less pronounced DD manifestations in the long-term (12 months) period demonstrated a better tolerance to physical activity and improved quality of life, as determined by the SAQ questionnaire and a lower rate of development cardiovascular complications.
\end{abstract}

KEY WORDS: ST segment elevation myocardial infarction, diastolic dysfunction, brain natriuretic peptide, primary stenting of coronary artery

Wiad Lek. 2020;73(1):68-72

\section{INTRODUCTION}

Initial coronary stent implantation improves the prognosis for patients with acute myocardial infarction (MI), influencing the left ventricle (LV) remodelling via improvement of diastolic function, which prevents the heart failure (HF) with reduced ejection fraction in the future [1]. Possibilities to diagnose left-ventricular diastolic dysfunction (DD) are rather limited, thus, this condition often remain not diagnosed during significantly long time. There are no specific clinical criteria featuring this pathology. However, taking into consideration the pathophysiological mechanisms related to LV diastolic pressure increase, which leads to the increasing of the Brain Natriuretic Peptide level, it was suggested that the level of the $\mathrm{N}$-final fragment - predecessor of the Brain Natriuretic Peptide (NT-proBNP) reflects the severity of DD in patients with LV preserved ejection fraction [2]. Analyzing the fluctuation of the NT-proBNP level, one can evaluate the effectiveness of the conservative and invasive treatments for these patients. In accordance with the references, in patients with the ST-elevation myo- cardial infarction (STEMI) the NT-proBNP concentration is lower after performance of initial percutaneous coronary intervention (PCI) than for patients who received only conservative therapy [3]. Analysis of the NT-proBNP level in the group with hemodynamically significant stenosis showed that it definitely increased in case the quantity of the damaged vessels increased, reflecting the size of the myocardial ischemia. Correspondingly, patients having one damaged vessel definitely had the lower NT-proBNP concentration, than those with two- and three-vessels damage [4]. Thus, the myocardial revascularization has a significant meaning for the prognosis improvement. Therefore, definition of the NT-proBNP level is an extremely important value while detecting the symptomless dysfunction of $\mathrm{LV}$, as well as while estimating the prognosis and monitoring of heart failure for these patients $[5,6]$.

In accordance with the theory of 'open artery', the patency of infarction- dependent coronary artery plays a key role in the LV re-modelling in patients with STEMI $[7,8]$. Renovation of the blood flow reduces the level of 
myocardial necrosis and spreading of infarction zone, thus improving prognosis. Besides, the particular importance is given to the modern 'microvasculature opening' theory. Research results showed that $30 \%$ of patients with STEMI, who received PCI, notwithstanding the full renovation of patency in infarction-dependent artery (IDA), got the dilatation of LV only 6 months after MI $[9,10]$. The reason for this may be the absence of the blood flow in coronary microcirculation, so-called 'no-reflow' phenomenon, which, notwithstanding the fully renovated IDA patency, leads to bigger tissue necrosis and higher frequency of complications [11-16]. Thus, it is important to identify and influence in time on main factors, predicting the negative remodeling of LV after MI, namely: absence of PCI for blood flow renovation through IDA and microvasculature; MI of the front LV wall; elevated NT-proBNP level and symptoms of heart failure at the moment and when a patient is discharged from the hospital [3].

The evaluation of echo-cardiographic DD parameters is really important for patients with STEMI on the early stage after PCI, as it can influence negatively on the prognosis. Among others, this is the detection of the restrictive type $\mathrm{DD}$ with the apparent decrease in the deceleration time of the early diastolic transmitral flow (DT) to less than $130 \mathrm{~ms}$ [17-19]. Several researchers showed that notwithstanding the correlation of the speed of early to the advanced transmitral flow (E/A), the DT slowing down in the post-infarction patients is the sign of the elevated pressure in the LV and leads to the increase of MI size [20-22]. This data is confirmed by Nijland F. and al., who informed that survival rates within one and three years after MI were only $50 \%$ and $22 \%$ correspondingly [23]. Poulsen S. and al. informed about the cardiologic mortality during the year for $43 \%$ of the patients with the pseudo-normal values of the restrictive DD type at the beginning of the MI onset [24].

Thus, it is reasonable to suggest that mechanic reperfusion with preservation of the IDA patency may suspend the process of the pathological LV remodeling or at least mitigate its negative influence on the LV remodeling, and improve the prognosis for those patients.

\section{THE AIM}

Aim of work - to evaluate the prognostic influence of the initial PCI on the 12 months left-ventricle remodeling in patients with STEMI and diastolic dysfunction.

\section{MATERIALS AND METHODS}

The research included 100 patients with confirmed STEMI, who were divided into two groups: 80 patients ( $1^{\text {st }}$ group) who have been performed PCI. The proportion of males was $68.1 \%$, females $-31.9 \%$, the mean age $-(56.7 \pm 7.3)$ years. The $2^{\text {nd }}$ group consists of 20 patients, who did not receive myocardial revascularization. This group included $75 \%$ males, $25 \%$ females, the mean age was $(66.1 \pm 7.3)$ years. Revascularization for the 2 nd group was not per- formed due to technical difficulties of CA stenting, late hospital admission (outwith the reperfusion window time), patients refusals and so on. Depending on the PCI performing time, patients of the $1^{\text {st }}$ group were split into three subgroups. PCI was performed within 12 hours of the onset of MI symptoms in patients of 1 A subgroup $(n=56)$, from 12 to 24 hours in patients of $1 B$ subgroup $(n=16)$ and after 24 hours in patients of $1 \mathrm{C}$ subgroup $(n=8)$.

All patients were examined on the $5^{\text {th }}$ day from the beginning of the MI and after 12 months (apart from coronary angiography). The traditional cardiovascular risk factors were identified as well as STEMI complications (MI relapse, rhythm and conductivity disorders, acute heart failure and sudden death). Apart from it, on the $21^{\text {st }}-28^{\text {st }}$ day the bicycle exercise was performed to establish the functional class of post-MI angina by the Canadian Cardiovascular Society angina (CCSA) classification.

Coronary angiography data (infarction-dependent artery localization, quantity of the damaged vessels) and PCI results were analyzed. Effectiveness of revascularization was evaluated by the TIMI coronary grade flow.

NT-proBNP plasma level was measured.

Transthoracic echocardiography was performed in accordance with the recent 2016 American Society of Echocardiography (ASE)/European Association of Cardiovascular Imaging (EACVI) recommendations in the prevalence and grade of DD. Diastolic dysfunction was diagnosed by transmitral early and advanced diastolic filling ratio (E/A ) and deceleration time (DT) of the early transmitral flow.

Quality of life was estimated according to the Seattle Angina Questionnaire (SAQ) by the following scales: PL (physical limitation), AS (angina stability), AF (angina frequency), TS (treatment satisfaction) and DP (disease perception) [25].

The treatment was performed in accordance with the ESC guidelines (2017) for Acute Myocardial Infarction in patients presenting with ST-segment elevation.

All patients received the ASA loading dose - $300 \mathrm{ng}$; Clopidogrel - $300 \mathrm{mg}$, and in case of PCI - additional loading dose of Clopidogrel - $300 \mathrm{mg}$ in $30 \%$ of patients and Ticagrelor - $180 \mathrm{mg}$ in $70 \%$ of cases with the following intake of the double anti-aggregate therapy in the standard dosage during 12 months; statin-therapy (Atorvastatin $40-80 \mathrm{mg}$ or Rosuvastatin $20-40 \mathrm{mg}$ ), and the accompanying background medicinal therapy in the form of: 90.2 \% - angiotensin-converting enzyme inhibitors (ACEi); $9.8 \%$ - Angiotensin II Receptor Blocker (ARB); $19.6 \%$ - mineralocorticoid receptor antagonist (MRA); $82.4 \%$ $\beta$ - adrenergic blocking agents; $4.8 \%$ - amiodarone; $45.3 \%$ - nitrates/sidnonimines. Besides, all patients of the 2-nd group received the low-molecular anticoagulants during the first 8 days, and the oral anticoagulants $-4.7 \%$ of the patients from the both groups, and the patients with the diabetes received the oral glucose-lowering medications $32.0 \%$, insulin - in $5.9 \%$.

Statistical processing of the data was performed with the help of the Statistica software and Microsoft Office Excel 2013 packet. The data is represented in the form of the 
average meaning and the standard error of the mean $(\mathrm{M} \pm$ $\mathrm{m})$. The authenticity of the differences between the groups according to the quantitative characteristics was evaluated with the help of the Student's t-criterion (in case of normal distribution). Differences were supposed to be authentic in case the significance level was $95 \%(\mathrm{p}<0.05)$.

\section{RESULTS AND DISCUSSION}

Risk factors in the $1^{\text {st }}$ group were: arterial hypertension $70.5 \%$, type 2 diabetes mellitus - $41.5 \%$, smoking habits - $40.9 \%$, hypercholesterolemia - $56.8 \%$ and overweight (mean body mass index was $29.4 \mathrm{~kg} / \mathrm{m}^{2}$ ). The 2 nd group revealed the similar structure of the risk factors: arterial hypertension - $80.5 \%$, type 2 diabetes mellitus - $48.5 \%$, smoking habits - $49.9 \%$, hypercholesterolemia - $66.8 \%$ with average body mass index of $29,1 \mathrm{~kg} / \mathrm{m}^{2}$. Medical history of the $1^{\text {st }}$ group reveled previous $\mathrm{MI}$ in $9.1 \%$, coronary artery bypass grafting or PCI - in $6.8 \%$, angina of the II-III CCSA class - in $15.9 \%$, atrial fibrillation - in $4.7 \%$, stroke - in $4.6 \%$ participants; in the 2 nd group: angina of the II-III CCSA class - in $21.4 \%$, previous MI - in $7.8 \%$, atrial fibrillation - y $8.1 \%$. Thus, in accordance with cardiovascular risk factors and the anamnestic data the two groups under research were alike.

Following the coronary angiography, among patients of the 1st group the infarction-dependent artery were localized in proximal and medial segments of left anterior descending artery (LAD) in 21 and 18 patients $(26.25 \%$ and $22.5 \%$ ) correspondingly, medial segment of circumflex artery (CfA) - 4 (5\%) patients, right coronary artery (RCA) - 37 (46.25\%) patients. In the 2 nd group LAD was occluded in $9(45 \%)$ patients, CfA - in 1 (5\%) patient, RCA - in 10 (50\%) patients.

In the 1st group multi-vascular lesioning of CA was observed in $16(20 \%)$ patients, two-vessels lesioning - in 24 (30\%), lesioning the one infarction-dependent artery was in $40(50 \%)$ cases. Complete revascularization (all arteries with stenosis $>70 \%$ were revascularized) was performed as the initial PCI in 45 patients (56.25\%). Incomplete revascularization - stenting of the infarction-dependent artery only - was performed in 35 patients (43.75\%) with the further complete revascularization after the $21 \mathrm{st}$ day from the onset of MI by the PCI in 20 (57.1\%) and coronary artery bypass grafting - in 2 (5.7 \%) patients. In $91 \%$ of cases we achieved TIMI 3 flow, in $9 \%$ of patients - TIMI 2 flow.

In the 2nd group the multi-vascular CA lesioning was observed in $50 \%$ of patients, two-vessel lesioning - in 30\% and lesioning of only one infarction-dependent artery - in $20 \%$ of patients.

NT-proBNP level on the 5-th day from the hospital admission corresponds to the 2-nd spike in patients with STEMI and authentically reflects the LV re-modeling process. Average NT-proBNP level in patients of the 2 nd group on the 5 -th day was $(1182.6 \pm 280.8) \mathrm{pg} / \mathrm{ml}$, and after 12 months lowered to $(629.3 \pm 82.2) \mathrm{pg} / \mathrm{ml}(\mathrm{p}>$ $0.05)$. Patients of the 1 st group had the significantly lower
NT-proBNP level on the 5th day and after 12 months correspondingly - $(434.6 \pm 36.3)$ i $(122.8 \pm 4.13) \mathrm{pg} / \mathrm{ml}(\mathrm{p}<$ $0,001)$, which shows the positive influence of myocardial revascularization on the LV remodeling process after the MI development.

The E/A ratio and DT in patients of the 1-st group were $(0.87 \pm 0.05)$ and $(186 \pm 2.8)$ ms correspondingly, and after 12 months $-(0.76 \pm 0.03)$ and $(198 \pm 4.7) \mathrm{ms}$ correspondingly, which certifies about the improvement of $L V$ relaxation processes $(\mathrm{p}<0.05)$. The $\mathrm{E} / \mathrm{A}$ ratio and $\mathrm{DD}$ values of patients of the 2-nd group appeared to be as follow $-(1.37 \pm 0.03)$ and $(145.75 \pm 2.91) \mathrm{ms}$ at the admision, and $(1.49 \pm 0.01)$ and $(135.3 \pm 2.91)$ after 12 months correspondingly, which is characteristic to the DD increase according to restrictive type $(\mathrm{p}<0.05)$. After 12 months the significant difference between two groups was observed $(\mathrm{p}<0.01)$.

Results of the evaluation of diastolic function and NT-proBNP level in patients of three sub-groups (1A$1 \mathrm{C}$ ) showed that postponed revascularization (more than 24 hours from the MI onset) has led to more significant $\mathrm{LV}$ remodeling in the form of the restrictive type of DD and higher levels of NT-proBNP in the 12 months period after the MI.

Comparative analysis of CA lesioning and NT-proBNP level in the 1st group showed the following results: in case of the multi-vascular CA lesioning the NT-proBNP was $(518.4 \pm 19.9) \mathrm{pg} / \mathrm{ml}$; two-vessels - $(470.0 \pm 10.5) \mathrm{pg} / \mathrm{ml}$; one-vessel lesioning - $(369.8 \pm 10.69) \mathrm{pg} / \mathrm{ml}(\mathrm{p}<0.05$ between groups). Thus, presence of the residual ischemia in case of the three-vessels or two-vessels CA lesioning, even after the successful PCI, is accompanied with the higher NT-proBNP level, which in future influences the speed and processes of the LV remodeling. That is why it is important to evaluate the full revascularization after 12 months by the estimation of NT-proBNP level. The group of patients discharged from the hospital with incomplete revascularization (coronary artery stenosis was present in more than $50 \%$ of arteries with the diameter $>2 \mathrm{~mm}$ ) comparing to the patients with full revascularization had the tendency to lowering of NT-proBNP level (126.5 \pm 7.1 ) $\mathrm{pg} / \mathrm{ml}$ and $(121.1 \pm 5.2) \mathrm{pg} / \mathrm{ml}$ correspondingly, which can certify about the effectiveness of full myocardium revascularization in patients with STEMI at hospital discharge.

Seattle Angina Questionnaire (SAQ) data showed that 1st group patients had better quality of life values comparing to the 2 nd group in distant period after MI.

Patients underwent the bicycle exercise tolerance test on the 21st-28th day after the STEMI beginning in order to define the angina functional class (FC). All 2-nd group patients had III-IV FC angina, while the 1st group patients had I-II FC. Thus, patients with undergoing PCI had better exercise tolerance to the physical loading. Unlike the patients of the 2 nd group whose exercise tolerance did not change within 12 months.

During the time in hospital the cardiovascular complications were evaluated. Group without PCI: 2 (10\%) patients died, in 1(5\%) complete AV heart block developed and in 
$1(5 \%)$ was detected ventricular tachycardia. PCI group: $1(1.25 \%)$ patient with inferior MI after PCI developed transient AV heart block, and in one case paroxysm of supraventricular tachycardia was detected, which was treated by intravascular injection of Amiodarone (1.25\%).

Within 12 month the percentage of current complications for the group with the performed PCI was $15 \%$ (3 (3.75\%) patients with atrial fibrillation, $5(4 \%)$ - hospital admission due to worsening of HF, 1(1.25\%) - subsequent MI, 3 (3.75\%) - unstable angina. In group without PCI the quantity of cardiovascular complications was $66.7 \%$. One (5.5\%) patient died (recurrent MI), 6 (33.3\%) patients had hospital readmission due to heart failure (50\% of them have atrial fibrillation), 5 (27.8\%) patients have unstable angina $(\mathrm{p}<0.05 \%)$.

\section{CONCLUSIONS}

1. Initial PCI in patients with STEMI leads to the significantly lower NT-proBNP level in the 12 months period, which reflects processes of pathologic LV remodeling, comparing to the group without revascularization.

2. Echo-cardiolographic features of diastolic function within 12 months in patients with STEMI and PCI was characterized with improvement of LV relaxation impairment and reduction in numbers of akinetic and hypokinetic segments. The group without PCI had markedly distinctive LV remodeling in the form of restrictive type of DD and reduction of LV ejection fraction from $55.0 \pm 4.5$ to $45.3 \pm 0.6 \%$.

3. During the first year of observation the patients with STEMI and PCI showed higher quality of life, with the sufficient exercise tolerance of the 1-2 angina FC, comparing to the group without revascularization (3-4 angina FC), and lower quality of life, according to SAQ scales.

4. In the group of patients without PCI there were more cardiovascular events (66.7\%) comparing to PCI group $(15 \%)(p<0.05 \%)$ within 12 months from the STEMI onset, which certifies about the worse prognosis in patients with STEMI without revascularization.

\section{REFERENCES}

1. Farahani $E$, Saadat $H$. The Effect of percutaneous coronary intervention on isolated left ventricular diastolic dysfunction in patients with coronary artery disease assessed by using strain rate imaging. J. Cardiol. Clin. Res.2014;2(3):1037.

2. Seino Y, Ogawa A, Yamashita T et al. Application of NT-proBNP and BNP measurements in cardiac care: A more discerning marker for the detection and evaluation of heart failure. Eur. J. Heart Failure.2004;6:295-300.

3. Zijlstra F, Hoorntje J, de Boer M et al. Long-term benefit of primary angioplasty as compared with thrombolytic therapy for acute myocardial infarction. N Engl J Med. 1999; 341: 1413-1419.

4. Spencer FA, MeyerTE, Goldberg RJ et al. Twenty year trends (1975-1995) in the incidence, in-hospital and long-term death rates associated with heart failure complicating acute myocardial infarction: a communitywide perspective. J Am Coll Cardiol.1999;34:1378-1387.
5. Doust JA, Pietrzak E, Dobson A et al. How well does B-type natriuretic peptide predict death and cardiac events in patients with heart failure: systematic review. BMJ. 2005; 330:625.

6. Silver MA, Maisel A, Yancy CW et al. BNP Consensus Panel 2004: A clinical approach for the diagnostic, prognosis, screening, treatment monitoring, and therapeutic roles of natriuretic peptides in cardiovascular diseases. Congest Heart Fail.2004;10(5 suppl 3):1-30.

7. Agewall S. How should we evaluate an open artery in STEMI patients? Eur Heart J.2005;26: 634-636.

8. Solomon A, Gersh B. The open-artery hypothesis. Annu Rev Med.1998;49:63-76.

9. Roe MT, Ohman EM, Maas ACP et al. Shifting the open-artery hypothesis downstream: the quest for optimal reperfusion. J Am Coll Cardiol.2001;37:9-18.

10. Bolognese L, Carrabba N, Parodi $G$ et al. Impact of microvascular dysfunction on left ventricular remodeling and long-term clinical outcome after primary coronary angioplasty for acute myocardial infarction. Circulation.2004;109:1121-1126.

11. Iwakura $\mathrm{K}$, Ito $\mathrm{H}$, Kawano $\mathrm{S}$ et al. Assessing myocardial perfusion with the transthoracic Doppler technique in patients with reperfused anterior myocardial infarction: comparison with angiographic, enzymatic and electrocardiographic indices.Eur Heart J.2004;25:1526-1533.

12. Topol EJ. Current status and future prospects for acute myocardial infarction therapy. Circulation.2003;108:16-13.

13. Bolognese L, Antoniucci D, Rovai D et al. Myocardial contrast echocardiography versus dobutamine echocardiography for predicting functional recovery after acute myocardial infarction treated with primary coronary angioplasty. J Am Coll Cardiol.1996;28:1677-1683.

14. Ito H, Maruyama A, Iwakura $K$ et al. Clinical implications of the 'noreflow' phenomenon. A predictor of complications and left ventricular remodeling in reperfused anterior wall myocardial infarction. Circulation. 1996;93:223-228.

15. Gibson CM, Murphy SA, Rizzo MJ et al. Relationship between TIMI frame count and clinical outcomes after thrombolytic administration. Thrombolysis in Myocardial Infarction (TIMI) Study Group. Circulation.1999;99:1945-1950.

16. Petronio AS, Rovai D, Musumeci $G$ et al. Effects of abciximab on microvascular integrity and left ventricular functional recovery in patients with acute infarction treated by primary coronary angioplasty. Eur Heart J.2003;24:67-76.

17. Michaels $A D$, Goldschlager N. Risk stratification after acute myocardial infarction in the reperfusion era. Prog Cardiovasc Dis.2000;42:273-309.

18. The Multicenter Postlnfarction Research Group. Risk stratification and survival after myocardial infarction.N Engl J Med.1983;309:321-336.

19. White HD, Norris RM, Brown MA et al. Left ventricular end-systolic volume as the major determinant of survival after recovery from myocardial infarction. Circulation.1987;76:44-51.

20. Cerisano G, Bolognese L, Carrabba N, et al. Doppler-derived mitral deceleration time: an early strong predictor of left ventricular remodeling after reperfused anterior acute myocardial infarction. Circulation. 1999;99:230-236.

21. Algom M, Schlesinger Z. Serial changes in left ventricular diastolic indexes derived from Doppler echocardiography after anterior wall acute myocardial infarction. Am J Cardiol. 1995;75:1272-1273.

22. Giannuzzi P, Imparato A, Temporelli PL, et al. Doppler-derived mitral deceleration time of early filling as a strong predictor of pulmonary capillary wedge pressure in post-infarction patients with left ventricular systolic dysfunction. J Am Coll Cardiol. 1994;23:1630-1637. 
23. Nijland F, Kamp 0, Karreman AJP et al. Prognostic implications of restrictive left ventricular filling in acute myocardial infarction: a serial Doppler echocardiographic study. J Am Coll Cardiol. 1997;30:16181624.

24. Poulsen SH, Jensen SE, Egstrup K. Longitudinal changes and prognostic implications of left ventricular diastolic function in first acute myocardial infarction. Am Heart J. 1999;137:910-918.

25. Spertus J.A., Winder J.A., Dewhurst T.A. et al. Development and evaluation of the Seattle Angina Questionnaire: a new functional status measure for coronary artery disease. J. Am. Coll. Cardiol.1995;25(2):333-341.

\section{ORCID and contributionship:}

Yurii P. Melen - 0000-0003-2919-8623 ${ }^{\text {A,B,D }}$

Vasyl A. Skybchik - 0000-0002-7140-0162 ${ }^{\mathrm{F}}$

Maryana Y. Fedechko - 0000-0002-9688-3420 C

Lesya M. Kopchak - 0000-0002-9342-4376 ${ }^{B, E}$

\section{Conflict of interest:}

The autors declare no conflict of interest

\section{CORRESPONDING AUTHOR}

Maryana Y. Fedechko

Lviv National Medical University

Cherkaska Str. 4/30, 79056, Lviv, Ukraina

tel.: +380678106687

e-mail:marianafed70@gmail.com

Received: 23.04 .2019

Accepted: 08.11.2019
A - Work concept and design, B - Data collection and analysis, C - Responsibility for statistical analysis,

D-Writing the article, $\mathbf{E}$-Critical review, $\mathbf{F}$ - Final approval of the article 